\title{
STUDI PUSTAKA TENTANG PENGARUH PERSEPSI MUTU PELAYANAN RAWAT JALAN DAN MUTU KONSULTASI DOKTER SPESIALIS TERHADAP KEPUASAN PASIEN DI RUMAH SAKIT
}

\author{
Riskiyana $^{1}$ \\ ${ }^{1}$ Program Studi Pendidikan Dokter Fakultas Kedokteran dan Ilmu-Ilmu Kesehatan \\ Universitas Islam Negeri Maulana Malik Ibrahim Malang \\ E-mail : riskiyananugroho.dr@gmail.com
}

\begin{abstract}
ABSTRAK
Pelayanan rawat jalan di rumah sakit merupakan pelayanan terhadap orang yang masuk rumah sakit, untuk keperluaan observasi diagnose, pengobatan, rehabilitasi medik dan pelayanan kesehatan lainya tanpa tinggal diruang rawat inap. Indikator utama untuk mengetahui mutu pelayanan rumah sakit adalah kepuasan pasien. Pelayanan yang baik dari suatu rumah sakit akan membuktikan bahwa rumah sakit tersebut bermutu baik. Kepuasan pasien merupakan penilaian pasien setelah merasakan pelayanan rawat jalan yang diberikan oleh petugas kesehatan seperti dokter spesialis dibandingkan dengan harapan pasien. Kualitas pelayanan yang baik merupakan salah satu faktor penting dalam usaha menciptakan kepuasan pasien di rumah sakit.
\end{abstract}

Kata Kunci : kualitas pelayanan, rumah sakit, pasien

\begin{abstract}
Outpatient services in hospitals are services to people admitted to the hospital, for the purposes of diagnose observation, treatment, medical rehabilitation and other health services without staying in the inpatient room. The main indicator to know the quality of hospital services is patient satisfaction. Good service from a hospital will prove that the hospital is of good quality. Patient satisfaction is the assessment of the patient after feeling the outpatient service provided by health care workers such as specialist doctors compared with patient expectations. Good service quality is one important factor in the effort to create patient satisfaction in hospital.
\end{abstract}

Keywords: service quality, hospital, patient 


\section{LATAR BELAKANG}

Menurut Undang-Undang Republik Indonesia Nomor 44 Tahun 2009 tentang rumah sakit, rumah sakit adalah institusi pelayanan kesehatan yang menyelenggarakan pelayanan kesehatan perorangan secara paripurna yang menyediakan pelayanan rawat inap, rawat jalan dan gawat darurat. Rumah sakit merupakan institusi pelayanan kesehatan bagi masyarakat dengan karateristik tersendiri yang dipengaruhi oleh perkembangan ilmu pengetahuan kesehatan, kemajuan teknologi, dan kehidupan sosial ekonomi masyarakat yang harus tetap mampu meningkatkan pelayanan yang lebih bermutu dan terjangkau oleh masyarakat agar terwujud derajat kesehatan yang setinggi-tingginya.

Dampak era globalisasi sudah mulai dirasakan di segala bidang kehidupan demikian pula dalam dunia perumahsakitan di Indonesia. Rumah sakit tidak lagi semata-mata sebagai suatu lembaga yang non profit melainkan sudah bergeser ke suatu lembaga profit yang bersifat sosial sehingga perlu dilakukan peninjauan kembali pada sistem manajemen pelayanan kesehatan khususnya jasa dibidang perumahsakitan. Rumah sakit yang di masa lalu dipandang sebagai misi sosial, untuk menyembuhkan orang sakit, sejak memasuki awal abad ke-21 berbagai tekanan lingkungan khususnya pengaruh kekuatan pasar memaksa pemilik dan pengelola rumah sakit berfikir untuk merubah sistem manajemennya(1). Adanya tekanan lingkungan berupa kondisi yang makin kompetitif mendesak setiap rumah sakit untuk meningkatkan mutu pelayanannya.

Pelayanan kesehatan yang bermutu adalah pelayanan kesehatan yang dapat memuaskan setiap pemakai jasa pelayanan kesehatan, sesuai dengan tingkat kepuasannya, rata-rata penduduk, serta yang penyelenggaraannya sesuai dengan standar dan kode etik profesi yang telah ditetapkan (2). Layanan kesehatan yang bermutu adalah suatu layanan kesehatan yang dibutuhkan, dalam hal ini akan ditentukan oleh profesi layanan kesehatan, dan sekaligus diinginkan baik oleh pasien/konsumen ataupun masyarakat serta terjangkau oleh daya beli masyarakat (3).

Setiap mereka yang terlibat dalam layanan kesehatan seperti pasien, masyarakat dan organisasi masyarakat, profesi layanan kesehatan, dinas kesehatan dan pemerintah daerah, pasti mempunyai pandangan yang berbeda tentang unsur apa yang penting dalam mutu layanan kesehatan. Perbedaan prespektif tersebut antara lain disebabkan oleh terdapatnya perbedaan dalam latar belakang, pendidikan, pengetahuan, pekerjaan, pengalaman, lingkungan dan kepentingan (4).

Perspektif mutu layanan kesehatan menurut pasien/masyarakat bahwa pasien/masyarakat melihat layanan kesehatan yang bermutu sebagai suatu layanan kesehatan yang dapat memenuhi kebutuhan yang dirasakannya dan diselenggarakan dengan cara yang sopan dan santun, tepat waktu, tanggap dan mampu menyembuhkan keluhannya serta mencegah berkembangnya atau meluasnya penyakit. Pandangan pasien/masyarakat ini sangat penting karena pasien yang merasa puas akan mematuhi pengobatan dan mau datang berobat kembali(4).

Perspektif mutu layanan kesehatan menurut pemberi layanan kesehatan (provider) mengaitkan layanan kesehatan yang bermutu dengan ketersediaan peralatan, prosedur kerja atau protokol, kebebasan profesi dalam setiap melakukan layanan kesehatan sesuai dengan teknologi kesehatan mutakhir dan bagaimana hasil layanan kesehatan tersebut. Profesi layanan kesehatan membutuhkan dan mengharapkan adanya dukungan teknis, administratif dan layanan pendukung lainnya (4). 
Penyandang dana atau asuransi kesehatan menganggap bahwa layanan kesehatan yang bermutu sebagai suatu layanan kesehatan yang efisien dan efektif. Pasien diharapkan dapat disembuhkan dalam waktu sesingkat mungkin sehingga biaya layanan kesehatan dapat menjadi efisien. Kemudian upaya promosi kesehatan dan pencegahan penyakit akan digalakkan agar penggunaan layanan kesehatan penyembuhan semakin berkurang (4).

Pemilik sarana layanan kesehatan yang bermutu merupakan layanan kesehatan yang menghasilkan pendapatan yang mampu menutupi biaya operasional dan pemeliharaan, tetapi dengan tarif layanan kesehatan yang masih terjangkau oleh pasien/masyarakat yaitu pada tingkat biaya ketika belum terdapat keluhan pasien dan masyarakat (4)

Sistem pelayanan rumah sakit terdiri dari banyak komponen dan salah satu komponen yang penting adalah pelayanan oleh dokter. Proses pelayanan seorang dokter terhadap kliennya merupakan produk jasa yang dapat dilihat, didengar, dirasakan dan diamati oleh pasien. Produk jasa pelayanan dokter di rumah sakit diberikan sejak pasien datang ke rumah sakit sampai selesainya pelayanan. Untuk itu dapat dikatakan bahwa proses pelayanan oleh seorang dokter merupakan pelayanan yang penting sehingga membutuhkan sikap dan perilaku tertentu sesuai dengan harapan dan persepsi pasien(5).

Pelayanan yang diberikan oleh dokter di rumah sakit terdiri dari berbagai macam bentuk pelayanan sesuai dengan unit kerja dan spesialisasinya. Pelayanan konsultasi yang diberikan oleh dokter merupakan pelayanan yang penting dan langkah pertama yang dialami pasien sebelum nantinya mendapatkan obat untuk mengatasi penyakitnya. Proses konsultasi tersebut terdiri dari beberapa komponen yaitu komunikasi interpersonal, komunikasi teraupetik (diagnosis), pemeriksaan, pengobatan yang disertai informasi mengenai obat, larangan dan instruksi (6).

Efektivitas konsultasi dengan dokter terdapat pada hubungan dokter-pasien yang terjadi selama proses konsultasi, dokter minimal mampu memahami dan memberikan penjelasan tentang informasi penting mengenai keadaan penyakit dan support emosional pasien. Oleh karena itu dokter perlu memahami model proses konsultasi yang baik (7).

Industri kesehatan dewasa ini berkembang dengan pesat baik dari sisi jumlah maupun kualitas. Semakin ketatnya persaingan bisnis dewasa ini dalam memperebutkan pelanggan dan perilaku pelanggan yang semakin selektif mengharuskan pihak manajemen suatu rumah sakit untuk memperhatikan kualitas pelayanannya.

\section{TINJAUAN PUSTAKA}

\section{Mutu Pelayanan}

Kualitas menurut Juran adalah fitness for use, yang mengandung pengertian bahwa suatu barang atau jasa harus dapat memenuhi apa yang diharapkan oleh para pemakainya. Menurut Crosby kualitas adalah conformance to requirement, yaitu sesuai dengan yang disyaratkan atau distandarkan. Sedangkan menurut Deming kualitas adalah kesesuaian dengan kebutuhan pasar (8).

Kualitas pelayanan adalah tingkat keunggulan yang diharapkan dan pengendalian atas tingkat keunggulan tersebut untuk memenuhi keinginan pelanggan (9). Menurut Parasuraman, et al (1988) bahwa kualitas layanan merupakan refleksi persepsi evaluatif konsumen terhadap pelayanan yang diterima pada suatu waktu tertentu. Ada dua faktor utama yang mempengaruhi kualitas layanan yaitu layanan yang diharapkan (expected service) konsumen dan layanan yang diterima atau dirasakan (perceived service) oleh konsumen. Apabila jasa yang diterima atau dirasakan sesuai dengan yang diharapkan, maka kualitas pelayanan dipersepsikan baik dan 
memuaskan. Jika kualitas pelayanan yang diterima melampaui harapan pelanggan, maka kualitas pelayanan dipersepsikan sebagai kualitas yang ideal, sebaliknya jika kualitas pelayanan yang diterima lebih rendah daripada yang diharapkan, maka kualitas pelayanan dipersepsikan buruk (10).

Pelayanan kesehatan yang bermutu adalah pelayanan kesehatan yang dapat memuaskan setiap pemakai jasa pelayanan kesehatan sesuai dengan tingkat kepuasan rata-rata penduduk, serta yang penyelenggaraannya sesuai dengan standar dan kode etik profesi yang telah ditetapkan (2). Layanan kesehatan yang bermutu adalah suatu layanan kesehatan yang dibutuhkan, dalam hal ini akan ditentukan oleh profesi layanan kesehatan, dan sekaligus diinginkan baik oleh pasien/konsumen ataupun masyarakat serta terjangkau oleh daya beli masyarakat(3).

Layanan kesehatan yang bermutu harus mempunyai paling sedikit tiga dimensi atau unsur yaitu dimensi konsumen, dimensi profesi dan dimensi manajemen atau dimensi proses. Dimensi Konsumen yaitu apakah layanan kesehatan itu memenuhi kebutuhan dan harapan pasien/konsumen yang selanjutnya diukur berdasarkan kepuasan atau keluhan pasien/konsumen. Dimensi profesi yaitu apakah layanan kesehatan memenuhi kebutuhan pasien/konsumen, diukur dengan menggunakan prosedur atau standar profesi yang diyakini akan member hasil dan kemudian hasil itu dapat pula diamati. Dimensi manajemen atau proses yaitu bagaimana proses layanan kesehatan menggunakan sumber daya yang paling efisien dalam memenuhi kebutuhan dan harapan pasien tersebut (4).

Parasuraman, et al (1988) menyusun dimensi pokok yang menjadi faktor utama penentu kualitas pelayanan jasa sebagai berikut (10):

a. Reliability (Keandalan), yaitu kemampuan untuk mewujudkan pelayanan yang dijanjikan dengan handal dan akurat.

b. Responsiveness (Daya tanggap), yaitu kemauan untuk membantu para konsumen dengan menyediakan pelayanan yang cepat dan tepat.

c. Assurance (Jaminan), yaitu meliputi pengetahuan, kemampuan, dan kesopanan atau kebaikan dari personal serta kemampuan untuk mendapatkan kepercayaan dan keinginan.

d. Empathy (Empati), yaitu mencakup menjaga dan memberikan tingkat perhatian secara individu atau pribadi terhadap kebutuhan-kebutuhan konsumen.

e. Tangibles (Buktilangsung), yaitu meliputi fasilitas fisik, peralatan atau perlengkapan, harga dan penampilan personal dan material tertulis.

Kelima dimensi tersebut diatas dikenal sebagai service quality (SERVQUAL). Dimensidimensi ini diperoleh melalui wawancara terhadap para konsumen untuk mengetahui apa saja yang diharapkan konsumen dari perusahaan tersebut (11). Dimensi kualitas layanan tersebut dapat dipergunakan untuk mengukur kualitas layanan suatu perusahaan jasa. Mengukur kualitas layanan berarti mengevaluasi atau membandingkan kinerja suatu jasa dengan seperangkat standar yang telah ditetapkan terlebih dahulu (9).

\section{Mutu Konsultasi Dokter Spesialis}

Dokter spesialis adalah seseorang yang telah menempuh pendidikan formal sesuai dengan katalog pendidikan yang dilaksanakan institusi yang diberi kepercayaan oleh pemerintah dan organisasi profesi (12). Dokter spesialis merupakan tenaga profesional yang memiliki daya tarik tinggi yang dapat memberikan daya saing dan keunggulan kompetitif bagi rumah sakit.

Mutu konsultasi adalah penilaian subyektif dari pasien, penilaian ini ditentukan oleh persepsi pasien terhadap produk atau jasa. Mutu pelayanan konsultasi di rumah sakit, dapat dilihat dari empat aspek yang berpengaruh terhadap penilaian sebagai berikut (13): 
a. Aspek klinis, yaitu yang menyangkut pelayanan kedokteran, ketepatan diagnosis, ketepatan terapi dan tentu kematian dan kesembuhan yang diperoleh.

b. Aspek efisiensi dan efektivitas, yaitu pelayanan yang murah, tepat guna dan terapi yang sesuai.

c. Aspek keselamatan, keamanan dan kenyamanan pasien, yaitu upaya perlindungan terhadap pasien seperti jatuh dari tempat tidur, kebocoran dll.

d. Kepuasan pasien, yaitu yang berhubungan dengan sikap empati (keramahan dan kecepatan pelayanan).

Proses konsultasi merupakan langkah pertama yang dialami pasien sebelum nanti mendapatkan obat untuk mengatasi penyakitnya yang terdiri dari komunikasi interpersonal, komunikasi terapeutik (diagnosis), pemeriksaan, pengobatan dan interaksi antara pasien dengan dokter sehingga dapat memecahkan masalah yang dihadapinya (6).

Hubungan terapeutik dokter-pasien merupakan pengalaman belajar timbal balik dan pengalaman emosional korektif bagi pasien. Komunikasi dapat memberikan nilai terapeutik, apabila komunikasi dapat memenuhi kebutuhan emosional dan intelektual. Kemampuan komunikasi terapeutik dokter sangat diperlukan agar pasien memahami tujuan dari pelayanan medik yang dilakukan (7).

Komunikasi terapeutik adalah Komunikasi yang direncanakan, disengaja dan merupakan tindakan profesional. Komunikasi terapeutik termasuk komunikasi interpersonal yaitu komunikasi transaksi antara pengirim dan penerima (14).

Empati adalah aspek kunci perjumpaan klinis antara pasien-dokter dan dipandang menjadi komponen dasar dari semua hubungan terapeutik. Sikap empati seorang dokter sangat diperlukan di dalam memberikan konsultasi kepada pasien(15).

Lama waktu untuk konsultasi merupakan aspek yang sangat penting diperhatikan dalam kunjungan pasien ke dokter spesialis, kepuasan mereka adalah identik ketika dapat berinteraksi dan bertatap muka dengan dokter tanpa tidak merasa terburu-buru dengan waktu. Durasi pemeriksaan yang semakin sedikit dapat menurunkan kepuasan pasien dan dokter, mengurangi perawatan pencegahan dan meningkatkan resiko malpraktek (16).

\section{Kepuasan Pasien}

Kepuasan pasien merupakan nilai subyektif terhadap kualitas pelayanan yang diberikan. Walaupun subyektif tetap ada dasar objektifnya, artinya penilaian tidak semata-mata menilai sesuatu kalau tanpa pengalaman yang dialami oleh pelanggan (13).

Kepuasan adalah suatu fungsi dari perbedaan antara penampilan yang dirasakan dengan harapan. Berdasarkan pengalaman di lapangan tingkat kepuasan pelanggan terhadap suatu objek layanan bervariasi dari tingkat kepuasan sangat puas, puas, kurang puas, tidak puas dan bahkan sangat tidak puas tergantung dari sikapnya terhadap ketidaksesuaian dan tingkatan evaluasi baik atau tidak untuk dirinya, melebihi atau dibawah standar(17). lain(18):

Kepuasan pengguna jasa pelayanan kesehatan dipengaruhi oleh beberapa faktor, antara

a. Pemahaman pengguna jasa tentang jenis pelayanan yang akan diterima, dimana aspek komunikasi berperan penting.

b. Empati (sikap peduli) yang ditujukan oleh petugas, sikap ini akan menyentuh emosi pasien.

c. Biaya (cost).

d. Penampilan fisik petugas, kondisi kebersihan dan kenyamanan ruangan (tangibility). 
e. Jaminan keamanan (assurance) berupa ketepatan jadwal pemeriksaan dan waktu kunjungan.

f. Keandalan dan ketrampilan (reliability) petugas dalam memberikan perawatan.

g. Kecepatan petugas dalam menanggapi keluhan pasien (responsiveness).

Aspek-aspek yang mungkin mempengaruhi kepuasan pasien khususnya di unit rawat jalan antara lain(3) :

a. Penampilan gedung rumah sakit meyakinkan dan menarik.

b. Lingkungan rumah sakit bersih, nyaman dan teratur.

c. Petunjuk arah/nama ruangan yang jelas dalam lingkungan rumah sakit.

d. Penampilan dokter/perawat/petugas kesehatan rapi, bersih dan bersikap mau menolong.

e. Poliklinik dan loket rekam medik yang buka tepat waktu.

f. Petugas yang melayani ramah, sopan dan tanggap.

g. Pencarian dan pengambilan rekam medik cepat dan tepat.

h. Giliran pemeriksaan oleh dokter tepat waktu.

i. Dokter menyapa dengan sopan, ramah, ingin membantu.

j. Dokter mau mendengarkan keluhan dengan penuh perhatian dan ingin menolong, melakukan pemeriksaan dengan teliti dan menyeluruh.

k. Dokter memberikan informasi tentang penyakit dan obat, serta memberi kesempatan bertanya.

1. Dokter memberi informasi yang dimengerti dan lengkap tentang penyakit.

m. Perawat selalu membantu dan berada dalam kamar periksa.

n. Kamar periksa yang bersih, rapi dan nyaman.

Tjiptono (19) mengatakan pelanggan memang harus dipuaskan, sebab kalau mereka tidak puas akan meninggalkan rumah sakit dan menjadi pelanggan pesaing, hal tersebut akan menyebabkan penurunan jumlah kunjungan pasien dan akan menurunkan keuntungan bahkan pihak rumah sakit akan mengalami kerugian.

Apabila rasa puas pelanggan itu dapat dicapai, maka akan diperoleh beberapa manfaat, seperti yang diuraikan oleh Tjiptono (19) yaitu :

a. Hubungan antara perusahaan dan para pelanggan akan terjalin dengan baik dan harmonis.

b. Mendorong terciptanya loyalitas dan kesetiaan pelanggan terhadap jasa yang dihasilkan.

c. Membentuk rekomendasi atau informasi dari mulut ke mulut yang dapat memberikan keuntungan bagi perusahaan.

d. Reputasi atau nama baik perusahaan tetap baik dan terjaga di kalangan para pelanggan.

e. Pangsa pasar dan laba perusahaan otomatis akan meningkat.

Atribut-atribut yang dapat membentuk kepuasan konsumen atas kualitas layanan yang terdiri atas(20) :

a. Guarantee or warranty adalah jaminan atau garansi yang diberikan oleh perusahaan yang bertujuan untuk memberikan pelayanan dan kepuasan pelanggan yang menggunakan produk tersebut.

b. Delivery communication adalah pesan atau informasi yang disampaikan oleh perusahaan kepada pelanggan. 
c. Complaint handling adalah sikap perusahaan untuk menerima keluhan dari pelanggan dari produk yang diberikan.

d. Resolution of problem adalah tanggapan perusahaan dalam membantu memecahkan permasalahan yang dihadapi oleh pelanggan berkaitan dengan layanan yang dikonsumsinya.

Rumah sakit yang sukses di masa mendatang adalah rumah sakit yang mempunyai sifat daya saing. Untuk memenangkan persaingan tersebut rumah sakit harus memberikan nilai dan kepuasan kepada pelanggan atau pasien melalui produk atau jasa yang berkualitas dengan biaya bersaing (21).

\section{DAFTAR PUSTAKA}

1. Trisnantoro, L., 2005, Aspek Strategis Dalam Manajemen Rumah Sakit, Andi Offset, Yogyakarta.

2. Azwar, 1996, Menjaga Mutu Pelayanan Kesehatan, Pustaka Sinar Harapan, Jakarta.

3. Pohan , I.S., 2007, Jaminan Mutu Layanan Kesehatan, Buku Kedokteran EGC, Jakarta.

4. Pohan , I.S., 2013, Jaminan Mutu Layanan Kesehatan, Buku Kedokteran EGC, Jakarta

5. Subanegara, H.P., 2005, Diamond Head Drill \& Kepemimpinan dalam Manajemen Rumah Sakit, $1^{\text {nd }}$ ed, Andi, Yogyakarta.

6. Ogden, J., 2004," I want more time my doctor" : a quantitive study of my time and consultation, Journal of Family Practice, Vol 21, No.5, p 479-493.

7. Zebiene, E., 2004, Meeting patient's expectations in primary care consultations in Lithuania, International Journal for Quality in Health Care; vol.16 No.1, p 83-89.

8. Nasution, M.N., 2005, Manajemen Mutu Terpadu (Total Quality Management), Ghalia Indonesia, Jakarta.

9. Tjiptono, F., 2002, Strategi Pemasaran, Edisi pertama, Cetakan Kedua, Penerbit Andi Offset, Yogyakarta.

10. Parasuraman, A., Zethaml, V.A, Berry, L.L., 1988. SERVQUAL : A Multiple Item For Measuring Consumer Perception of service Quality, Journal of Retailing, 64(1) , 12-40.

11. Bustami. 2011. Penjaminan Mutu Pelayanan Kesehatan \& Akseptabilitasnya. Jakarta : Erlangga

12. Soeroso, S., 2003, Manajemen Sumber Daya Rumah Sakit : Suatu Pendekatan Sistem, $1^{\text {st }}$ ed, Penerbit Buku Kedokteran ECG, Jakarta.

13. Sabarguna, B.S., 2004, Quality Assurance Pelayanan Rumah Sakit, Konsorsium RSI JatengDIY, Yogyakarta.

14. Mulyana, D., 2001, Ilmu Komunikasi Suatu Pengantar, PT Remaja Rosda Karya, Bandung.

15. Stewart, M.W., 2004, The Consultation and Relational Emphaty Measure; Development and Preliminary Validation and reability of an Emphaty-Based Consultation Process Measure, Journal of Family Practice, Vol 21, No.6, p 699-705.

16. Tan Lin, C., Alberston, A.G., schilling, M.L, cyran, M.E., Anderson, N. S., ware, L, Anderson, J.R., 2001, Is Patients Perception of Time Splent With The physician a 
Determinant of Ambulatory patient Satisfaction, Arch Inter Med, Vol 161, No.5, p 14371442.

17. Wijono, 2000, Manajemen Mutu Pelayanan Kesehatan, Teori, Strategi dan Aplikasi. Vol 1, Edisi kedua, Airlangga University Press, Surabaya.

18. Muninjaya, 2004, Manajemen Kesehatan, Penerbit Buku Kedokteran EGC, Jakarta.

19. Tjiptono, F., 1996, Service, Quality \& Satisfaction, Edisi pertama, Penerbit Andi Offset, Yogyakarta

20. Dutka. A., 1994, American Marketing Association, AMA Handbook for Customer Satisfaction, NTC Business Book.

21. Kotler, P., 2004, Manajemen Pemasaran, Jilid 1, Edisi 6, Erlangga, Jakarta. 